\title{
Risk perception and information-seeking behaviour during the 2009/10 influenza A(H1N1)pdm09 pandemic in Germany
}

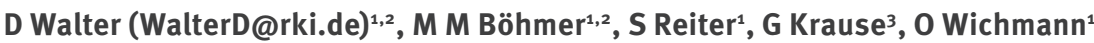

1. Immunization Unit, Robert Koch Institute, Berlin, Germany

2. Charité Medical School - University Medicine Berlin, Berlin, Germany

3. Department for Infectious Disease Epidemiology, Robert Koch Institute, Berlin, Germany

Citation style for this article:

Walter D, Böhmer MM, Reiter S, Krause G, Wichmann O. Risk perception and information-seeking behaviour during the $2009 / 10$ influenza A(H1N1)pdmo9 pandemic in Germany.

Euro Surveill. 2012;17(13):pii=20131. Available online: http://www.eurosurveillance.org/ViewArticle.aspx?Articleld=20131

Article published on 29 March 2012

During the influenza $\mathrm{A}\left(\mathrm{H}_{1} \mathrm{~N}_{1}\right)$ pdmog pandemic in $2009 / 10$, a total of 13 consecutive surveys were carried out of the general population in Germany to monitor knowledge, attitude and behaviour concerning the disease and vaccination against pandemic influenza in real time. In total, 13,010 persons aged 14 years or older were interviewed by computer-assisted telephone techniques between November 2009 and April 2010. During the peak of the pandemic, only $18 \%$ of participants stated that they perceived the risk of pandemic influenza as high; this proportion fell to $10 \%$ in January 2010. There was a significant difference in information-seeking behaviour among population subgroups concerning the disease and vaccine uptake. However, in all subgroups, conventional media sources such as television, radio and newspapers were more frequently used than the Internet. While the majority of participants (78\%) felt sufficiently informed to make a decision for or against vaccination, overall vaccination coverage remained low. Among those who decided against vaccination, fear of adverse events and perception that the available vaccines were not sufficiently evaluated were the most frequently stated reasons. Such mistrust in the vaccines and the perceived low risk of the disease were the main barriers that contributed to the low vaccination coverage in Germany during the pandemic.

\section{Introduction}

After the first description of a novel influenza $A\left(\mathrm{H}_{1} \mathrm{~N}_{1}\right)$ virus in April 2009, the virus rapidly spread worldwide. While many countries experienced a first pandemic wave in the middle of 2009 , Germany was initially affected by imported cases followed by an acceleration of cases mainly due to travellers and their contacts in the summer of 2009 [1]: at the end of September, there was an increase in the number of reported autochthonous influenza $A\left(\mathrm{H}_{1} \mathrm{~N}_{1}\right)$ pdmog cases, followed by a sharp increase in the number of cases from October onwards, which peaked in the middle of November (week 46) [2].

In September 2009, the German Standing Committee on Vaccination (STIKO) recommended that people in target groups - people at occupational risk (including healthcare workers), persons with underlying chronic diseases and pregnant women - should be vaccinated against influenza $A\left(\mathrm{H}_{1} \mathrm{~N}_{1}\right)$ pdmog. The vaccination campaign officially started at the end of October 2009 (week 44), when pandemic vaccines became available. In Germany, an ASo3-adjuvanted vaccine was almost exclusively used, with a one-dose recommendation for all age groups. With the availability of large numbers of vaccine doses, in mid-December 2009, the Committee expanded its recommendation to the general population, but still with prioritisation of the target groups mentioned above [3]. Although the vaccine was shown to be highly effective in protecting against pandemic influenza [4], vaccine uptake remained low among the general public and even among those in vaccination target groups [5].

Research into knowledge, attitude and behaviour in the context of a pandemic can not only guide communication and mitigation strategies during the event, but can also inform future pandemic preparedness planning. Data can be collected via online or telephone surveys, which - if analysed ad hoc - can provide insights into public perceptions related to the disease and implemented control measures in real time. In Germany, we conducted 13 consecutive cross-sectional knowledge, attitude and behaviour surveys to monitor the vaccination campaign against pandemic influenza in the general population in 2009/10. Our primary objective was to assess vaccine uptake in different target groups. Details of target group-specific vaccination coverage have been published previously [5]. Here we present data from the surveys related to public perception of the disease and relevant vaccination as 
well as information seeking-behaviour during the pandemic. The analysis aimed to identify possible pivotal points and needs for future communication planning in situations with pandemic potential and immunisation campaigns.

\section{Methods}

\section{Cross-sectional telephone surveys}

A series of 13 computer-assisted telephone interview surveys took place from 16 November (week 47) 2009 to 14 April (week 14) 2010. The first nine were carried out every two weeks, until 10 March; the final four, from 22 March to 14 April (weeks 12-15) 2010, were weekly. The first survey took place about three weeks after the official start of the influenza $A\left(\mathrm{H}_{1} \mathrm{~N}_{1}\right)$ pdmog vaccination campaign in Germany.

The survey methodology has been published previously [5]: in brief, each survey was conducted with a representative sample of approximately 1,000 households. The surveys included a core set of questions: other questions were changed, included or deleted in surveys over the study period to monitor new or upcoming topics of research or to adjust to changing situations. Because of that, each analysis refers to the particular surveys in which the questions of interest were included. The interviews were conducted by forsa (Gesellschaft für Sozialforschung und statistische Analysen $\mathrm{mbH}$ ), a large market research company with extensive experience in health-related surveys, as part of forsa's daily omnibus survey in Germany, a continuing multi-topic survey primarily used for market research.

Interviews were performed according to the data protection standards used by forsa, which include obtaining oral informed consent before starting the interview. Trained interviewers surveyed randomly selected German-speaking individuals, aged 14 years and older, living in private households equipped with a telephone. In each household contacted, the last-birthday selection method was applied [6]. Interviews were usually conducted on workdays in the afternoon or evening, but appointments were also made if requested. The survey samples were weighted for region, age, sex and educational level on the basis of recent population projections of the Federal Statistical Office of Germany [7].

To monitor vaccine uptake as well as knowledge and attitude related to pandemic influenza, we used a core set of questions in all 13 surveys, e.g. questions on immunisation against pandemic or seasonal influenza, as well as questions designed to categorise interviewees into specific target groups for vaccination as defined by the German Standing Committee on Vaccination. Socio-demographic information (e.g. age, sex, educational level) was assessed as part of the omnibus survey. Furthermore, interviewees were asked to judge how high they perceived the threat imposed by pandemic influenza to their personal health, how well informed they felt about the disease and vaccination against pandemic influenza, the information sources they used during the pandemic and the perceived risk related to the vaccination.

\section{Statistical analysis}

Statistical analysis was performed using PASW version 18.0 for Windows (SPSS, United States). Univariable and multivariable analyses were performed using the complete set or subsets of survey data. A two-sided $p$ value of less than 0.05 was considered to indicate a statically significant difference. Statistical independence was tested using logistic regression models. Multivariate analysis was performed using multiple logistic regression models with combined stepwise backward removal and forward selection. Odds ratios $(\mathrm{OR})$ and $95 \%$ confidence intervals $(\mathrm{Cl})$ were calculated. Variables potentially associated with vaccine uptake ( $p<0.2$ in univariable analysis) were entered into a multivariate logistic regression model in a first step, followed by stepwise backward removal of variables with a $p$ value greater than or equal to 0.05 to produce $a$ final model.

Variables were categorised as follows: age group (aged 14-24, 25-59, $\geq 60$ years), sex (male/female), geographical region (west/east), level of education (low: nine years or less of school education; medium: at least 10 years of school education; high: university entrance diploma), community size $(\leqslant 5,000 ; 5,001-$ 20,000; 20,001-100,000; 100,001-500,000; >500,000 inhabitants), whether in a vaccination target group, as defined by German Standing Committee on Vaccination (persons with underlying chronic diseases, people at occupational risk and pregnant women).

For questions requiring agreement or disagreement, four categories were possible: full or partial agreement and full or partial disagreement. Data were weighted with respect to the inclusion probability depending on geographical region, age, sex and level of education of the participants. All statistical analyses were performed using the weighted data.

\section{Results}

A total of 13,010 telephone-interviews were conducted in the 13 cross-sectional surveys. The first nine surveys, conducted every two weeks, comprised 9,005 participants and the final four weekly surveys, which were identical, a total of 4,005 . As the interviews were part of the omnibus survey, which has an ongoing inclusion of telephone numbers, a precise response rate cannot be determined. The average response rate in the omnibus survey was approximately $45 \%$ and the refusal rate $26 \%$. The median age of all respondents was 48 years (range: $14-93$ ) with $52.5 \%$ of the interviewed persons being female.

Risk perception related to pandemic influenza During the first nine surveys, the 9,005 respondents answered questions about the perceived threat of pandemic influenza to their personal health. The first 
survey took place at about the same time most influenza $A\left(\mathrm{H}_{1} \mathrm{~N}_{1}\right)$ pdmog cases per week were notified to the national disease surveillance system in Germany (Figure). Risk perception (i.e. risk due to 'swine flu' perceived as great or partially great) fell in the general population from about $18 \%$ in November 2009 (week 47) to a plateau of approximately $10 \%$ in the surveys in December 2009 (weeks 51 and 53) and January 2010 (weeks 2 and 4). Over the same time period, there was an increase in the proportion of respondents who stated that their perception of risk was low, from about $34 \%$ in the initial survey (week 47 ) to approximately $65 \%$ in March 2010 (week 10). The risk perception over the first nine surveys among all interviewed persons, among those who were aged 60 years or older and among those belonging to the target vaccination groups is shown in the Figure.

In the final four weekly surveys, during March and April $2010,70 \%$ of the 4,005 interviewees agreed fully and $10 \%$ agreed partially to the statement that in retrospect at no point in time had they felt a special threat to their personal health due to 'swine flu'.

In two surveys in January 2010 (weeks 2 and 4), we asked participants about the potential influence of the media coverage on their risk perception related to pandemic influenza in Germany. Among the 1,000 respondents in the mid-January survey (week 2), $68.2 \%$ agreed fully and $16.1 \%$ agreed partially to the statement that media reporting about pandemic influenza had been exaggerated. Furthermore, $33.0 \%$ of the 1,004 respondents at the end of January (week 4) agreed fully and $12.0 \%$ agreed partially to the statement that media reporting about the vaccine had led to a feeling of uncertainty.

\section{Informedness about pandemic influenza}

In the first six surveys (those until the end of January 2010 (week 4)), we asked how well informed the participants felt about pandemic influenza. In the first survey, $17.7 \%$ of the 1003 respondents stated that they were 'not well' informed and $28.5 \%$ 'partially not well'. Over the time course of these six surveys, the proportion of 6005 respondents who did not feel well or partially not well informed fell to $10.2 \%$ and $21.5 \%$, respectively. In the pooled data set of the first six surveys, the proportion of respondents who felt well or partially well informed increased by level of education (59.3\% with a low level of education, $64.5 \%$ with a medium level and $69.7 \%$ with a high level; for comparisons at all educational levels, $p$ <0.001) and decreased with age (age group 14-24 years: $72.7 \%$; 25-59 years: 64.2\%; $\geq 60$ years: $61.0 \%$; for comparisons in all age groups: p<0.001). Respondents who were not immunised against pandemic influenza stated more frequently

\section{FIGURE}

Proportion of respondents who perceived a great or partially great threat due to pandemic influenza in the first nine surveys, by population subgroup, 16 November (week 47) 2009-10 March (week 10) 2010 ( $\mathrm{n}=9,005)$ and epidemic curve of pandemic influenza cases (case reports)

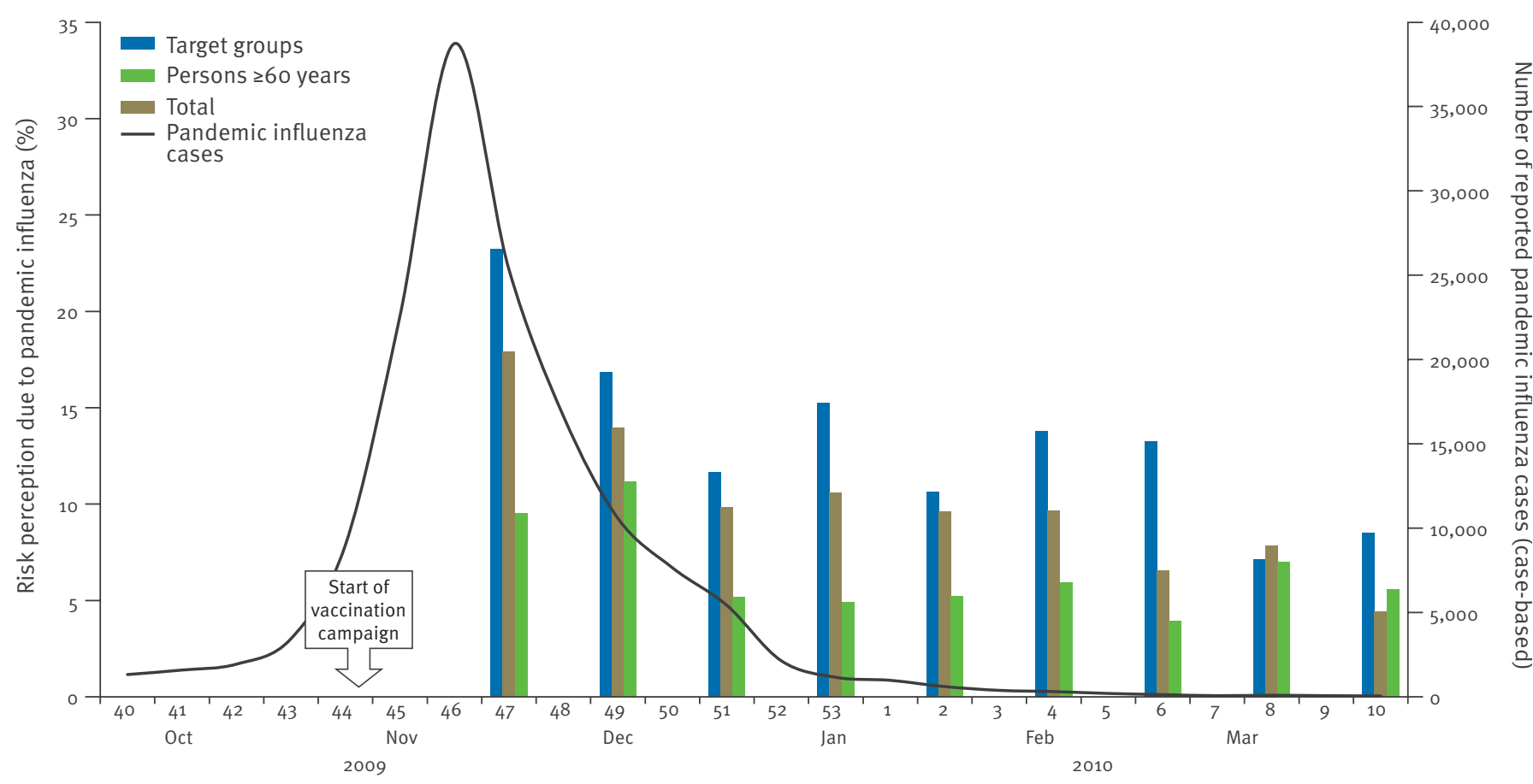

Calendar week 
to be not well or partially not well informed about the disease compared with those respondents who were immunised (35.9\% v. 28.2\%; p<0.05).

\section{Information sources used to find}

\section{out about pandemic influenza}

Between mid-November and the end of December 2009 (weeks 47-53) - a period with substantial spread of pandemic influenza in the population - we asked 4,003 participants about the sources used to gather information about the disease. The main sources of information were the mass media, such as television and radio (71.2\%; 95\% Cl: 69.3-73.0), as well as print media, such as magazines or newspapers $(58.6 \%$; $95 \% \mathrm{Cl}: 56.6-60.7)$. The Internet was used by $27.6 \%$ (95\% Cl: $26.0-29.4)$ as a source of information, but when stratifying by age group - only by $10.2 \%$ (95\% $\mathrm{Cl}: 8.3-12.4)$ of persons 60 years and older. Friends and relatives were mentioned as an important source of information by $56.1 \%(95 \% \mathrm{Cl}: 54.1-58.1)$ and physicians by $31.0 \%$ (95\% Cl: 29.1-32.8). Some 3.1\% (95\% $\mathrm{Cl}: 2.4-4.0)$ stated not to have used any kind of information source.

Respondents belonging to the vaccination target groups used physicians more frequently $(38.0 \% \mathrm{v}$. $28.1 \%$; p $<0.001$ ) and peers less frequently (51.4\% v. $58.0 \%$; p $<0.01$ ) as a source of information related to the disease when compared with the respondents who were not in a target group. Physicians were used as a source of information about the disease by $62.1 \%$ of respondents who had been vaccinated against pandemic influenza, in contrast to $28.8 \%$ of respondents who had not received the vaccine ( $p<0.001)$. There was, however, no statistically significant association between any source used to gather information on the disease in general and the uptake of influenza $A\left(\mathrm{H}_{1} \mathrm{~N}_{1}\right)$ vaccine.

\section{Informedness and attitude related to}

\section{pandemic influenza vaccination}

In the final four surveys $(n=4,005)$, we asked how well informed the respondents felt about issues related to pandemic influenza vaccination. In total, 78.4\% (95\% $\mathrm{Cl}: 75.1-81.6)$ agreed fully or partially to the statement that they felt sufficiently informed during the pandemic to make a decision for or against vaccination. Only $23.8 \%$ (95\% Cl: $22.1-25.6$ ) agreed fully and $11.3 \%$ (95\% Cl: 10.1-12.6) agreed partially that they lacked neutral and factual information. However, 55.3\% (95\% $\mathrm{Cl}$ : 51.8-59.0) fully and partially had the feeling that official authorities had not informed the public openly and honestly about issues related to the vaccination.

Stratified analysis showed that $91.8 \%$ (95\% Cl: 87.694.6) of respondents who had been vaccinated agreed fully or partially that they were sufficiently informed to make a balanced vaccination decision, while only $78.1 \%$ (95\% Cl: 76.2-79.9) of those who had not been vaccinated felt well informed ( $p<0.001)$. There was also a significant difference in the number of respondents who agreed that official authorities had informed the public openly and honestly about pandemic influenza vaccination when comparing vaccinated with unvaccinated respondents $(63.0 \%$ v. $41.1 \%$; p $<0.001)$.

\section{Use of information sources related to pandemic influenza vaccination}

Data on sources used to gather information on vaccination against pandemic influenza was available from the 4,005 persons interviewed in the final four surveys. There was a significant difference in information-seeking behaviour among population subgroups (Table 1). When compared with younger age groups, respondents aged 60 years or older obtained information significantly more frequently from conventional media sources such as radio, television, newspapers, and magazines. The Internet as well as information materials of official health authorities were less frequently used by all age groups compared with conventional media sources. Internet use for this purpose increased significantly with higher educational level. Physicians as a source of information related to vaccination were mentioned more frequently by older age groups and almost twice as frequently by vaccinated compared with unvaccinated respondents (Table 1 ). Persons who belonged to a vaccination target group used the Internet less frequently (21.6\% v. $26.9 \%$; p $<0.01)$ and their physician more frequently $(42.1 \% \mathrm{v}$. $29.8 \%$; p $<0.001$ ) as source of information compared with respondents not in the target groups.

We used univariable and multivariable logistic regression models to explore potential associations between the source of information about vaccination and vaccine uptake by using data from the final four surveys (Table 2). After adjusting for possible confounders (i.e. age, sex, whether in a vaccination target group, education level, community size and region), we found that use of radio or television (OR: $0.62 ; 95 \% \mathrm{Cl}: 0.48-0.81$ ) as well as family and friends (OR: 0.72 ; $95 \% \mathrm{Cl}: 0.55-$ 0.94 ) as a main source of information were independently associated with lower vaccine uptake. In contrast, an association with vaccine uptake and the search for information about vaccination was found when physicians (OR: $2.77 ; 95 \% \mathrm{Cl}: 2.16-3.57$ ) or official materials (OR: $2.07 ; 95 \% \mathrm{Cl}: 1.55^{-2.77)}$ were used as a main source of information. Use of the Internet as a main information source for vaccination was not associated with pandemic influenza vaccination in our study population (Table 2).

\section{Reasons for not being immunised against pandemic influenza}

In all 13 surveys over the whole study period, we asked persons who were not vaccinated against pandemic influenza and did not intend to be the reason why they objected to vaccination. Fear of adverse events of the vaccine was given as a reason for not being vaccinated in approximately $20 \%$; the perception that the vaccines were insufficiently tested was stated in $15 \%$. An additional $14 \%$ stated that their decision against 
the vaccination was triggered by 'public panicking and overhyping' and approximately $10 \%$ stated that they felt vaccination was just not necessary. Lack of information about the vaccine or information about possible side effects was mentioned in $2 \%$. The proportion of respondents who stated they had a fear of adverse events decreased by age (chi-square test for trend, $p<0.001$ ) and was lowest in those aged 60 years or older (13.5\%). In mid-January 2010 , we asked the survey participants $(n=1,000)$ if they believed that the adjuvant in the pandemic vaccine was safe. Of those, $8 \%$ agreed fully and $10 \%$ partially.

\section{Discussion}

Our survey results provide important insights into public opinion and information-seeking behaviour related to the influenza pandemic and vaccination campaign in Germany in 2009/10. The findings of the survey are generally in line with those conducted in other countries during the pandemic [8,9]. In Germany, vaccine uptake was particularly low, even in vaccination target groups, and communication practices might have contributed to this fact [5]. Our findings suggest that a perceived low risk related to the disease and concerns about the safety of available vaccines were the main barriers to pandemic influenza vaccination.

The first of the 13 consecutive surveys was carried out during the peak of the pandemic wave and at the early phase of the vaccination campaign. Therefore, we were not able to monitor trends in risk perception from the beginning of the pandemic in spring 2009. However, even during the peak of pandemic influenza in Germany, we observed that the level of perceived risk was low. Similar findings were reported from
Australia in 2009, where risk perception was low even during times of high likelihood of acquiring the virus [10]. Risk perception in our survey fell further at the beginning of 2010 and was particularly low in persons aged 60 years and older.

According to the health belief model, risk perception (which is usually defined by the expected probability of an event and its severity) and believing that preventive measures are safe and effective are the main factors influencing a vaccination decision [11]. A literature review assessing factors that influence preventive behaviour during pandemic situations highlighted that perceived susceptibility to and severity of the disease as well as believing in the effectiveness of protective measures increased its implementation [12]. A low-tomoderate risk perception related to pandemic influenza and lack of concern was observed in surveys in various industrialised countries during 2009/10, for example in Italy [13], the Netherlands [14], Australia [15] and the United States [16].

Public risk perceptions may be directly modulated by media coverage, and media-triggered public concern was shown to be an important factor for health-related personal measures during the influenza pandemic as shown in studies in, for example, the United States [17] or France [18]. While there are studies showing that media coverage can have a positive influence on disease perception and willingness to be vaccinated against seasonal influenza $[19,20]$, the reception of media output during an influenza pandemic needs to be analysed carefully [21]. In Europe, the initial media attention, related to the occurrence of a new pandemic influenza strain in 2009, was found to be high [22].

\section{TABLE 1}

Sources used to gather information on vaccination against pandemic influenza, by population subgroup, Germany, final four surveys, 22 March-14 April (weeks 11-15) 2010 (n=4,005)

\begin{tabular}{|c|c|c|c|c|c|c|c|c|c|c|c|}
\hline \multirow{3}{*}{ Source of informationa } & \multicolumn{11}{|c|}{ Percentage of respondents } \\
\hline & \multirow{2}{*}{$\begin{array}{c}\text { Total } \\
n=4,005\end{array}$} & \multicolumn{2}{|c|}{$\begin{array}{c}\text { Vaccinated } \\
\text { against pandemic } \\
\text { influenza }\end{array}$} & \multicolumn{2}{|c|}{ Sex } & \multicolumn{3}{|c|}{ Age group (in years) } & \multicolumn{3}{|c|}{ Educational level ${ }^{b}$} \\
\hline & & $\begin{array}{c}\text { Yes }^{c} \\
n=324\end{array}$ & $\begin{array}{c}\text { No } \\
\mathrm{n}=3,676\end{array}$ & $\begin{array}{c}\text { Male }^{c} \\
\mathrm{n}=1,948\end{array}$ & $\begin{array}{c}\text { Female } \\
\mathrm{n}=2,057\end{array}$ & $\begin{array}{l}14-24 \\
n=555\end{array}$ & $\begin{array}{c}25-59 \\
n=2,261\end{array}$ & $\begin{array}{c}\geq 60^{c} \\
n=1,170\end{array}$ & $\begin{array}{c}\text { Low }^{c} \\
\mathrm{n}=1,706\end{array}$ & $\begin{array}{l}\text { Medium } \\
\mathrm{n}=1,094\end{array}$ & $\begin{array}{l}\text { High } \\
\mathrm{n}=965\end{array}$ \\
\hline Radio or television & 64.6 & 53.0 & $65.6^{* \star *}$ & 63.7 & 65.3 & $51.9^{\star \star \star}$ & $64 \cdot 5^{\star \star \star}$ & 70.9 & 68.3 & 65.8 & $59 \cdot 5^{\star \star \star}$ \\
\hline Newspapers or magazines & 50.0 & 47.4 & 50.3 & 49.4 & 50.5 & $35.2^{\star \star \star}$ & $49.6^{* \star *}$ & 58.2 & 50.1 & 49.9 & 53.6 \\
\hline Family and friends & 42.8 & 39.5 & 43.1 & 39.4 & $45 \cdot 9^{\star \star \star}$ & $47.0^{\star * \star}$ & $46.9^{\star \star \star}$ & 33.1 & 38.6 & $46.6^{\star \star \star}$ & $45.6^{* \star \star}$ \\
\hline Physician & 34.0 & 66.9 & $31.1^{\star \star \star}$ & 30.0 & $37 \cdot 7^{\star \star \star}$ & $26.0^{\star \star \star}$ & $33.8^{\star \star}$ & 38.3 & 36.6 & 35.2 & $31.6^{\star}$ \\
\hline Internet & 25.1 & 21.9 & 25.4 & 26.0 & 24.3 & $31.5^{\star \star \star}$ & $31.1^{\star \star \star}$ & 10.9 & 17.2 & $27.2^{\star \star \star}$ & $37.2^{\star \star \star}$ \\
\hline $\begin{array}{l}\text { Information materials from } \\
\text { official authorities }\end{array}$ & 13.4 & 22.9 & $12.6^{\star \star \star}$ & 11.5 & $15.2^{\star \star}$ & $12.6^{\star \star}$ & $16.4^{\star \star \star}$ & 8.2 & 8.6 & $16.7^{\star \star \star}$ & $19.1^{\star \star \star}$ \\
\hline Other sources of information & 2.8 & 3.5 & 2.7 & 2.2 & $3 \cdot 3^{*}$ & $3.2^{*}$ & $3.5^{* * *}$ & 1.3 & 1.9 & $3.2^{*}$ & $3.2^{*}$ \\
\hline No active information-seeking & 5.7 & 0.0 & 6.2 & 7.2 & $4.2^{\star \star \star}$ & $12.1^{\star \star \star}$ & 4.7 & 4.3 & 6.2 & 5.2 & $4.2^{*}$ \\
\hline
\end{tabular}

* $p<0.05,{ }^{* *} p<0.01, * * * p<0.001$.

a Multiple answers were possible.

b Low: nine years or less of school education; medium: at least 10 years of school education; high: university entrance diploma.

Reference group. 
Systematic content analysis, for example, of television reports in Australia [23] or print media in the United Kingdom [24] and in the German city of Bremen [25], did not show that reports on pandemic influenza were scaremongering. Our data, however, suggest a public sentiment of media exaggerating the situation in Germany. Use of television and radio as a main source of information was associated with lower vaccine uptake compared with use of other sources. This finding is consistent with studies showing that uncertainty about the pandemic situation and perceived exaggeration of the situation is associated with a reduced likeliness to implement the recommended behaviour [26].

In general, the Internet is regarded as an important source of information for the general public on health-related topics: therefore, relevant and highquality information should be made available online [27]. Nonetheless, in our survey, use of the Internet was found to be low compared with other information sources. The Internet does not seem to be effective in reaching certain population groups such as elderly people or those with a low educational level.

\section{TABLE 2}

Univariable and multivariable analysis of the association of the source of information about the vaccine and vaccination against pandemic influenza, Germany, final four surveys, 22 March-14 April (weeks 11-15) 2010 $(\mathrm{n}=4,005)$

\begin{tabular}{|l|c|c|c|}
\hline \multirow{4}{*}{ Source of information } & $\begin{array}{c}\text { Used } \\
\text { or } \\
\text { not }\end{array}$ & $\begin{array}{c}\text { Univariable } \\
\text { analysis }\end{array}$ & $\begin{array}{c}\text { Multivariable } \\
\text { analysis }^{\mathrm{a}}\end{array}$ \\
\cline { 3 - 5 } Radio or television & No & $95 \% \mathrm{Cl})$ & OR $(95 \% \mathrm{CI})$ \\
\cline { 2 - 4 } & Yes & $\begin{array}{c}0.56 \\
(0.46-0.72)\end{array}$ & $\begin{array}{c}0.62 \\
(0.48-0.81)\end{array}$ \\
\hline \multirow{2}{*}{$\begin{array}{l}\text { Newspaper or } \\
\text { magazines }\end{array}$} & No & $1^{\mathrm{b}}$ & - \\
\cline { 2 - 4 } & Yes & $\begin{array}{c}0.84 \\
(0.67-1.05)\end{array}$ & NS \\
\hline \multirow{3}{*}{ Family and friends } & No & $1^{\mathrm{b}}$ & - \\
\cline { 2 - 4 } & Yes & $\begin{array}{c}0.75 \\
(0.59-0.95)\end{array}$ & $\begin{array}{c}0.72 \\
(0.55-0.94)\end{array}$ \\
\hline \multirow{3}{*}{ Physician } & No & $1^{\mathrm{b}}$ & - \\
\cline { 2 - 4 } & Yes & $\begin{array}{c}3.37 \\
(2.67-4.26)\end{array}$ & $\begin{array}{c}2.77 \\
(2.16-3.57)\end{array}$ \\
\hline \multirow{3}{*}{ Internet } & No & $1^{\mathrm{b}}$ & - \\
\cline { 2 - 4 } & Yes & $\begin{array}{c}0.93 \\
(0.72-1.20)\end{array}$ & NS \\
\hline \multirow{2}{*}{$\begin{array}{l}\text { Information materials } \\
\text { from official authorities }\end{array}$} & No & $1^{\mathrm{b}}$ & - \\
\cline { 2 - 4 } & Yes & $2.1(1.66-2.78)$ & $\begin{array}{c}2.07 \\
(1.55-2.77)\end{array}$ \\
\hline \multirow{2}{*}{$\begin{array}{l}\text { Other sources of } \\
\text { information }\end{array}$} & No & $1^{\mathrm{b}}$ & - \\
\hline & Yes & $\begin{array}{c}2.08 \\
(1.25-3.49)\end{array}$ & $\begin{array}{c}2.26 \\
(1.29-3.95)\end{array}$ \\
\hline
\end{tabular}

$\mathrm{Cl}$ : confidence interval; OR: odds ratio; NS = not significant.

a Adjusted for age, sex, whether in a vaccination target group, educational level, community size, region.

b Reference category.
Although Internet use was found to be lower than expected in our study, the impact of specific online communication, such as the use of social media, was not assessed. Nevertheless, the spread of information through informal online networks and peer-to-peer communication might have had considerable impact on vaccination decisions during the pandemic. This has been shown in Japan, where informal networks of communication were influential in sharing safety information on pandemic influenza vaccine [28]. A survey of Hong Kong adults supports the finding that trust in informal information sources may be linked to the perceived health risk related to pandemic influenza and avoidance behaviour [29]. Using family and friends as a main source of information was shown to be negatively associated with vaccine uptake in our study. This finding corroborates the hypothesis that peer-to-peer communication is of high importance in a pandemic [30].

Concern about the safety of the pandemic vaccines was identified as a major barrier to vaccination in our study population. This was consistently observed in many studies assessing factors influencing vaccination decision [11]. In Greece, for example, fear about vaccine safety was the most frequently mentioned reason against vaccination [31]. Although we found that the majority of respondents felt sufficiently informed to make a balanced vaccination decision, information about the safety and benefits of the pandemic vaccine was obviously not convincing enough to reach satisfactory immunisation rates in the population. In a situation of high uncertainty about risks, trust in public bodies may be a crucial factor for the success of public health measures. Building and maintaining trust should therefore be a long-term task, involving all stakeholders [30]. The observed mistrust in the safety and usefulness of the pandemic vaccines stresses that information campaigns primarily focusing on the safety of pandemic vaccines may not be sufficient in a situation of low risk perception related to the disease [32].

Physicians were considered an important source of information, in particular regarding vaccination decisions, among respondents who were in vaccination target groups. Therefore informing healthcare professionals about the risks and benefits of the vaccine can be regarded crucial to increasing vaccination coverage. Public trust in medical organisations was shown to be an important factor for pandemic influenza vaccination decisions in Switzerland [33]. In our study, being informed by physicians and use of information material of official authorities were independently associated with vaccination against pandemic influenza. Surveys in the United States showed that persons who reported use of information from healthcare providers and official sources were more frequently convinced about the seriousness of pandemic influenza and the usefulness of the immunisation [34]. In an Italian survey, not only concerns and risk perception, but also trust in the media and official bodies were associated with compliance to the recommended behaviour [35]. In our study, 
however, a considerable proportion of participants had the feeling that official authorities had not informed the public openly and honestly about issues related to the vaccines.

A limitation of our study is that bias due to the telephone sample procedures cannot be excluded. Household-based telephone surveys may have limited access to certain groups such as people who use exclusively mobile phones or persons living in nursing homes. Furthermore, the survey represents only German-speaking persons: individuals without German-language skills might use different patterns of information sources. On the other hand, however, using a standard omnibus survey, which contained topics not related to the study, may have reduced potential bias due to rejection or higher interest in the study topic. Results of our surveys were furthermore weighted to control for possible selection biases.

In conclusion, on the basis of the results of our surveys - which began shortly after start of the vaccination campaign - we were able to demonstrate that the pandemic influenza vaccination campaign in Germany took place when public risk perception related to the disease was low, while scepticism and misconceptions about the pandemic influenza vaccine and implemented measures were frequent. These findings are in line with surveys of other countries conducted during the pandemic $[8,9]$ but add the first insights into the situation in Germany, where vaccine uptake was particularly low. Rebuilding trust in recommendations of public health authorities and addressing common misinformation about immunisation against pandemic influenza will be a communication challenge when preparing for future pandemic situations and for vaccination policies in general [30]. The pre-pandemic development of tailormade information strategies accompanied by surveys to monitor public perception implemented early in the pandemic should be considered for future pandemic preparedness planning and the mitigation of health threats on a population level.

\section{Acknowledgments}

The authors thank all staff of the Department for Infectious Disease Epidemiology at the Robert Koch Institute who were involved in the management of the influenza $A\left(\mathrm{H}_{1} \mathrm{~N}_{1}\right)$ pandemic.

\section{References}

1. Poggensee G, Gilsdorf A, Buda S, Eckmanns T, Claus H, Altmann D, et al. The first wave of pandemic influenza $\left(\mathrm{H}_{1} \mathrm{~N}_{1}\right)$ 2009 in Germany: from initiation to acceleration. BMC Infect Dis. 2010;10:155.

2. Buda S, Köpke K, Haas W. Epidemiologischer Steckbrief der pandemischen Influenza $\left(\mathrm{H}_{1} \mathrm{~N}_{1}\right) 2009$ basierend auf Einzelfallmeldungen nach Infektionsschutzgesetz. [Epidemiological characteristics of the influenza pandemic $\left(\mathrm{H}_{1} \mathrm{~N}_{1}\right) 2009$ in Germany based on the mandatory notification of cases]. Bundesgesundheitsblatt Gesundheitsforschung Gesundheitsschutz. 2010;53(12):1223-30. German.

3. Mitteilung der Ständigen Impfkommission (STIKO) am Robert Koch-Institut Impfung gegen die Neue Influenza A ( $\left.\mathrm{H}_{1} \mathrm{~N}_{1}\right)$.
[Recommendation of the Standing Vaccination Commission (STIKO) at the Robert Koch Institute - vaccination against novel influenza $A\left(\mathrm{H}_{1} \mathrm{~N}_{1}\right)$ ]. Epidemiologisches Bulletin. 2009(50):51319. German. Available from: http://www.rki.de/cln_109/ nn_1378492/DE/Content/Infekt/EpidBull/Archiv/2009/50__09, templateld=raw, property=publicationFile.pdf/50_09.pdf

4. Wichmann O, Stöcker P, Poggensee G, Altmann D, Walter $D$, Hellenbrand W, et al. Pandemic influenza $A\left(\mathrm{H}_{1} \mathrm{~N}_{1}\right) 2009$ breakthrough infections and estimates of vaccine effectiveness in Germany 2009-2010. Euro Surveill, 2010;15(18):pii=19561. Available from: http://www.eurosurveillance.org/ViewArticle. aspx?Articleld $=19561$

5. Walter D, Böhmer MM, Heiden M, Reiter S, Krause $\mathrm{G}$,Wichmann O. Monitoring pandemic influenza $A\left(\mathrm{H}_{1} \mathrm{~N}_{1}\right)$ vaccination coverage in Germany $2009 / 10$ - results from thirteen consecutive cross-sectional surveys. Vaccine. 2011;29(23):4008-12.

6. Lind K, Link M, Oldendick R. A comparison of the accuracy of the last birthday versus the next birthday methods for random selection of household respondents. Proceedings of the Survey Research Methods Section, American Statistical Association. Alexandria, VA: American Statistical Association; 2000. p. 887-9. Paper presented at the 55th Annual Conference of the American Association for Public Opinion Research \&World Association for Public Opinion Research, 17-21 May 2000, Portland, Oregon. Available from: http://www.amstat. org/sections/srms/proceedings/papers/2000_151.pdf

7. German Federal Statistical Office. Population. Wiesbaden: German Federal Statistical Office. [Accessed 28.02.2012]. Available from: http://www.destatis.de/jetspeed/portal/ cms/Sites/destatis/Internet/EN/Navigation/Statistics/ Bevoelkerung/Bevoelkerung.psml

8. Bish A, Yardley L, Nicoll A, Michie S. Factors associated with uptake of vaccination against pandemic influenza: a systematic review. Vaccine. 2011;29(38):6472-84

9. Nguyen T, Henningsen KH, Brehaut JC, Hoe E,Wilson K. Acceptance of a pandemic influenza vaccine: a systematic review of surveys of the general public. Infect Drug Resist. 2011;4:197-207.

10. Seale H, Heywood AE, McLaws ML, Ward KF, Lowbridge CP, Van D, et al. Why do I need it? I am not at risk! Public perceptions towards the pandemic $\left(\mathrm{H}_{1} \mathrm{~N}_{1}\right) 2009$ vaccine. BMC Infect Dis. 2010;10:99.

11. Poland GA. The 2009-2010 influenza pandemic: effects on pandemic and seasonal vaccine uptake and lessons learned for seasonal vaccination campaigns. Vaccine. 2010;28 Suppl 4:D3-13.

12. Bish A, Michie S. Demographic and attitudinal determinants of protective behaviours during a pandemic: a review. $\mathrm{Br}$ J Health Psychol. 2010;15(Pt 4):797-824.

13. Ferrante G, Baldissera S, Moghadam PF, Carrozzi G, Trinito MO, Salmaso S. Surveillance of perceptions, knowledge, attitudes and behaviors of the Italian adult population (18-69 years) during the $2009-2010 \mathrm{~A} / \mathrm{H}_{1} \mathrm{~N}_{1}$ influenza pandemic. Eur J Epidemiol. 2011;26(3):211-9.

14. Bults M, Beaujean DJ, de Zwart O, Kok G, van Empelen P, van Steenbergen JE, et al. Perceived risk, anxiety, and behavioural responses of the general public during the early phase of the influenza $A\left(\mathrm{H}_{1} \mathrm{~N}_{1}\right)$ pandemic in the Netherlands: results of three consecutive online surveys. BMC Public Health. 2011;11:2.

15. Eastwood K, Durrheim D, Francis IL, d'Espaignet ET, Duncan $\mathrm{S}$, Islam F, et al. Knowledge about pandemic influenza and compliance with containment measures among Australians. Bull World Health Organ. 2009;87(8):588-94.

16. Steelfisher GK, Blendon RJ, Bekheit MM, Lubell K. The public's response to the $2009 \mathrm{H}_{1} \mathrm{~N}_{1}$ influenza pandemic. N Engl J Med. 2010;362(22):e65.

17. McDonnell WM, Nelson DS,Schunk JE. Should we fear "flu fear" itself? Effects of $\mathrm{H}_{1} \mathrm{~N}_{1}$ influenza fear on ED use. Am J Emerg Med. 2012;30(2):275-82.

18. Nougairède A, Lagier JC, Ninove L, Sartor C, Badiaga S, Botelho $E$, et al. Likely correlation between sources of information and acceptability of $\mathrm{A} / \mathrm{H}_{1} \mathrm{~N}_{1}$ swine-origin influenza virus vaccine in Marseille, France. PLoS One. 2010;5(6):e11292.

19. Yoo BK, Holland ML, Bhattacharya J, Phelps CE, Szilagyi PG. Effects of mass media coverage on timing and annual receipt of influenza vaccination among Medicare elderly. Health Serv Res. 2010;45(5 Pt 1):1287-309.

20. Ma KK, Schaffner W, Colmenares C, Howser J, Jones J, Poehling KA. Influenza vaccinations of young children increased with media coverage in 2003. Pediatrics. 2006;117(2):e157-63.

21. Falagas ME, Kiriaze IJ. Reaction to the threat of influenza pandemic: the mass media and the public. Crit Care. 2006;10(2):408 
22. Duncan B. How the media reported the first days of the pandemic $\left(\mathrm{H}_{1} \mathrm{~N}_{1}\right)$ 2009: results of EU-wide media analysis. Euro Surveill. 2009;14(30): pii=19286. Available from: http://www. eurosurveillance.org/ViewArticle.aspx?Articleld=19286

23. Fogarty AS, Holland K, Imison M, Blood RW, Chapman S, Holding S. Communicating uncertainty--how Australian television reported $\mathrm{H}_{1} \mathrm{~N}_{1}$ risk in 2009: a content analysis. BMC Public Health. 2011;11:181.

24. Hilton S, Hunt K. UK newspapers' representations of the 200910 outbreak of swine flu: one health scare not over-hyped by the media? J Epidemiol Community Health. 2011;65(10):941-6.

25. Schmidt F, Tempel G. Medienanalyse zur pandemischen Influenza (H1N1) 2009 - zur Rolle der Tageszeitungen in Bremen [Media analysis of pandemic Influenza (H1N1) 2009 - The role of newspapers in Bremen]. Epidemiologisches Bulletin. 2010(25):239-41. German. Available from: http://www.rki.de/ cln_109/nn_1759378/DE/Content/Infekt/EpidBull/Archiv/2010 /25__10,templateld=raw, property=publicationFile.pdf/25_10. pdf

26. Rubin GJ, Amlôt R, Page L,Wessely S. Public perceptions, anxiety, and behaviour change in relation to the swine flu outbreak: cross sectional telephone survey. BMJ. 2009;339:b2651.

27. Gesualdo F, Romano M, Pandolfi E, Rizzo C, Ravà L, Lucente D, et al. Surfing the web during pandemic flu: availability of World Health Organization recommendations on prevention. BMC Public Health. 2010;10:561.

28. Nakada H, Murashige N, Matsumura T, Kodama Y, Kami M. Informal network of communication tools played an important role in sharing safety information on $\mathrm{H}_{1} \mathrm{~N}_{1}$ influenza vaccine. Clin Infect Dis. 2010;51(7):873-4.

29. Liao Q, Cowling B, Lam WT, Ng MW, Fielding R. Situationa awareness and health protective responses to pandemic influenza $A\left(\mathrm{H}_{1} \mathrm{~N}_{1}\right)$ in Hong Kong: a cross-sectional study. PLoS One. 2010;5(10):e13350.

30. Larson HJ, Heymann DL. Public health response to influenza $\mathrm{A}\left(\mathrm{H}_{1} \mathrm{~N}_{1}\right)$ as an opportunity to build public trust. JAMA, 2010;303(3):271-2.

31. Sypsa V, Livanios T, Psichogiou M, Malliori M, Tsiodras S, Nikolakopoulos I, et al. Public perceptions in relation to intention to receive pandemic influenza vaccination in a random population sample: evidence from a cross-sectional telephone survey. Euro Surveill. 2009;14(49): $\mathrm{pii}=19437$. Available from: http://www.eurosurveillance.org/ViewArticle. aspx?Articleld=19437

32. Raude J, Caille-Brillet AL, Setbon M, The 2009 pandemic $\mathrm{H}_{1} \mathrm{~N}_{1}$ influenza vaccination in France: who accepted to receive the vaccine and why? PLoS Curr. 2010;2:RRN1188.

33. Gilles I, Bangerter A, Clémence A, Green EG, Krings F, Staerklé $C$, et al. Trust in medical organizations predicts pandemic $\left(\mathrm{H}_{1} \mathrm{~N}_{1}\right) 2009$ vaccination behavior and perceived efficacy of protection measures in the Swiss public. Eur J Epidemiol. 2011;26(3):203-10.

34. Maurer J, Uscher-Pines L,Harris KM. Perceived seriousness of seasonal and $A\left(H_{1} N_{1}\right)$ influenzas, attitudes toward vaccination, and vaccine uptake among U.S. adults: does the source of information matter? Prev Med. 2010;51(2):185-7.

35. Prati G, Pietrantoni L, Zani B. Compliance with recommendations for pandemic influenza $\mathrm{H}_{1} \mathrm{~N}_{1}$ 2009: the role of trust and personal beliefs. Health Educ Res. 2011;26(5):761-9. 